\title{
Desaturations During 6-Minute Walk Test and Predicting Nocturnal Desaturations in Adult Subjects With Cystic Fibrosis
}

\author{
Rosa Mar Gómez Punter, Rosa M Girón Moreno, Emma Vázquez Espinosa, Joan B Soriano, \\ M Teresa Pastor, Enrique Zamora, Claudia Valenzuela, Tamara Alonso, Elena García Castillo, and \\ Julio Ancochea
}

\begin{abstract}
BACKGROUND: Nocturnal desaturation in cystic fibrosis (CF) may have prognostic implications because a significant and maintained nocturnal desaturation can contribute to the development and progression of pulmonary hypertension with cor pulmonale. Its relation with the desaturation in exercise has not been sufficiently studied. We aimed to determine whether desaturation during 6MWT can be an indicator of nocturnal desaturation in adult subjects with CF. METHODS: 57 subjects were included: $50.9 \%$ male, $27.5 \pm 7.7 \mathrm{y}$ old, mean $\mathrm{FEV}_{1}=2.37 \pm 0.74 \mathrm{~L}$, and $\% \mathrm{FEV}_{1}$ $67 \pm 18.1 \%$. Desaturation during $6 \mathrm{MWT}$ was defined as oxygen saturation $\left(\mathrm{S}_{\mathrm{pO}_{2}}\right) \leq 90 \%$ or a decline of $>4$ points in $\mathrm{S}_{\mathrm{pO}_{2}}$ from baseline, and nocturnal desaturation as a desaturation index $>4$ or $>5 \%$ of sleep time with $\mathrm{S}_{\mathrm{pO}_{2}} \leq 90 \%$. RESULTS: Desaturation observed during 6MWT in adult subjects with $\mathrm{CF}$ did not correlate with nocturnal desaturation $(P=.27)$. Subjects with $\% \mathrm{FEV}_{1}$ $\leq \mathbf{5 5 \%}$ and diffusion capacity of carbon monoxide $\left(\mathrm{D}_{\mathrm{LCO}}\right) \leq \mathbf{5 0} \mathrm{mmol} / \mathrm{min} / \mathrm{mm} \mathrm{Hg}$ were at higher risk of 6MWT desaturation. Nocturnal desaturation was more frequent in males, with $\mathrm{P}_{\mathrm{aO}}$ $\leq 71 \mathrm{~mm} \mathrm{Hg}$ in blood gas analysis. CONCLUSIONS: Desaturation observed in 6MWT cannot predict desaturation at night in adults with CF. Other parameters were identified as predictors of desaturation. Key words: saturation; walk; pulse oximetry; sleep; oxygen; exercise; hypoxemia. [Respir Care 2019;64(1):48-54. (C) 2019 Daedalus Enterprises]
\end{abstract}

\section{Introduction}

Cystic fibrosis (CF) is one of the most common genetic diseases in whites, ${ }^{1,2}$ with an incidence of about 1 in 5,000 live births in Spain. ${ }^{2}$ It is an autosomal recessive inheritance disease that affects exocrine glands of different organs and systems, causing abnormal secretions that produce obstruction and favor infection. Just a few de-

\footnotetext{
The authors are affiliated with the Servicio de Neumología. Instituto de Investigación Sanitaria Princesa (IISP), Hospital Universitario La Princesa, Universidad Autónoma de Madrid, Madrid, Spain.
}

The authors have disclosed no conflicts of interest.

Supplementary material related to this paper is available at http:// www.rcjournal.com.

Correspondence: Rosa Mar Gómez Punter, Servicio de Neumología. Hospital Universitario de la Princesa, C/Diego de León 62, 28006, Madrid, Spain. E-mail: rosamar_gp@hotmail.com.

DOI: $10.4187 /$ respcare. 06171 cades ago, mortality in $\mathrm{CF}$ was high, with a median survival $<4$ y. However, significant improvement in survival has been recently seen. In the United States in 2015, according to the Cystic Fibrosis Foundation, CF median survival was $41.6 \mathrm{y} .^{3}$

In subjects with respiratory diseases, exercise tests have been extensively used to provide information about prognosis and disability, to determine the presence of exercise hypoxemia, and to assess response to treatment. Cardiopulmonary exercise testing is used as a standard test, but it has many limitations due to technical complexity and costs; therefore, in recent years the 6-min walk test (6MWT) has been increasingly used. The 6MWT consists of measuring the maximum distance a person can walk in $6 \mathrm{~min}$. This distance has been shown to indirectly predict morbidity and mortality. ${ }^{4}$

The clinical value of the 6MWT test in adults with CF has been insufficiently studied. Most available studies have been done in small groups or in assessments of lung transplantations. The work of Martin et $\mathrm{al}^{5}$ performed in adults with stable $\mathrm{CF}$ and varying degrees of pulmonary obstruc- 
tion showed that a $6 \mathrm{MWT}$ distance $\leq 475 \mathrm{~m}$ or desaturation $\left(\mathrm{S}_{\mathrm{pO}_{2}} \leq 90 \%\right)$ during the test were associated with increased risk of lung transplantation or death without transplantation.

On the other hand, sleep studies show that hypoxemia and hypercapnia occur as a result of a reduction in respiratory activity and tidal volume and a loss of functional residual capacity, especially during rapid eye movement sleep. ${ }^{6}$ Decreased $\mathrm{S}_{\mathrm{pO}_{2}}$ that occurs during sleep is more pronounced in patients with $\mathrm{CF}$ than in normal individuals. A significant and maintained nocturnal desaturation can contribute to a development and progression of pulmonary hypertension with cor pulmonale. .-8 $^{-8}$

$\mathrm{CF}$ guidelines recommend an annual exercise tolerance test or measurement of blood gases (eg, pulse oximetry, capnography, arterial blood gases). ${ }^{9}$ In patients presenting with an $\mathrm{FEV}_{1} \leq 50 \%$ or with resting $\mathrm{S}_{\mathrm{pO}_{2}}=93-94 \%$, nocturnal pulse oximetry is recommended. ${ }^{9}$ There are few studies of subjects with $\mathrm{CF}$ where nocturnal desaturation were measured. ${ }^{8}$ Furthermore, there is no universally agreed definition of desaturation, which complicates standardization.

To date, available studies linking desaturation during sleep with that during exercise in subjects with CF have been mostly performed in children. ${ }^{10,11}$ To our knowledge, there are no reports exploring desaturation with 6MWT and nocturnal pulse oximetry in adults with $\mathrm{CF}$.

We aimed to determine whether measurements of pulse oximetry desaturation during the 6MWT could be a good predictor of nocturnal desaturation in adult subjects with $\mathrm{CF}$. Secondary objectives were to determine the relationships between 6MWT and nocturnal desaturation with lung function, quality of life measured by the Cystic Fibrosis Questionnaire-Revised (CFQ-R), and body mass index (BMI).

\section{Methods}

We included subjects diagnosed with CF who were $\geq 18 \mathrm{y}$, followed up in a specialized CF unit in Madrid, Spain. ${ }^{12,13}$ Inclusion criteria were clinical stability during the previous 4 weeks (ie, no exacerbations requiring treatment modification or hospital admission), the ability to understand and comply with the procedures, and the ability to give informed consent. The research protocol was approved by the Ethics Committee, and all participants provided written informed consent. Exclusion criteria were patients requiring home oxygen therapy, patients with previous lung transplant and any motor neuromuscular disorder, and patients who could not perform the 6MWT in the opinion of the principal investigator.

Subjects were referred to the Functional Respiratory Exploration Laboratory, where both a baseline arterial blood gas analysis and 6MWT were performed. Later, in the sleep unit, subjects were given a pulse oximeter capable of storing $\mathrm{S}_{\mathrm{pO}_{2}}$ data overnight.

\section{QUICK LOOK}

\section{Current knowledge}

The clinical value of the 6-min walk (6MWT) test in adults with cystic fibrosis has been insufficiently studied. Desaturations that occur during sleep are more pronounced in individuals with cystic fibrosis. A significant and maintained nocturnal desaturation can contribute to the development and progression of pulmonary hypertension with cor pulmonale.

\section{What this paper contributes to our knowledge}

We measured nocturnal desaturation via pulse oximetry and 6MWT desaturation in adult subjects with cystic fibrosis. Desaturation during 6MWT did not correlate with nocturnal desaturation in this population.

Collected clinical variables included sex, age, genetic mutation, pancreatic insufficiency, diabetes or glucose intolerance, impaired bone mineral density, occurrence of previous bronchial infection, and non-infectious respiratory complications (eg, massive hemoptysis, recurrent pneumothorax, atelectasis or allergic bronchopulmonary aspergillosis) and digestive complications. BMI was calculated as weight in kilograms divided by height in meters squared $\left(\mathrm{kg} / \mathrm{m}^{2}\right) .{ }^{14}$ Information about the number of exacerbations and treatment in the previous year, including the use of health care resources, were collected.

The Shwachman-Kulczycki, ${ }^{15}$ Brasfield, ${ }^{16}$ and modified Bhalla ${ }^{17}$ scores were used for the assessment of clinical status. Spirometry was performed using a spirometer (Vmax Sensormedics, CareFusion, San Diego, California). Collected data consisted of FVC in L and as a percentage compared to a theoretical value according to age, height, and sex; $\mathrm{FEV}_{1}$ in $\mathrm{L}$ and as a percentage of its theoretical value, and the ratio $\mathrm{FEV}_{1} / \mathrm{FVC}$. In addition, we registered the results of the most recent plethysmography prior to the study and determination of diffusing capacity for carbon monoxide $\left(\mathrm{D}_{\mathrm{LCO}}\right)$. The CFQ- ${ }^{18}$ questionnaire was used for the assessment of quality of life in subjects with CF. The 6MWT was performed according to American Thoracic Society standards. ${ }^{19}$ We recorded distance walked, $\mathrm{S}_{\mathrm{pO}_{2}}$, and heart rate every minute and at the end of the test, along with dyspnea using the Borg scale at the beginning and end of testing. Our definition of desaturation during the 6MWT was a minimum $\mathrm{S}_{\mathrm{pO}_{2}} \leq 90 \%$ or a drop of $>4$ points between initial and final baseline $\mathrm{S}_{\mathrm{pO}_{2}}{ }^{11}$

Pulse oximetry (PulseOx-7500, SPO, Kfar Saba, Israel) was used with a digital sensor and a monitor, and the $\mathrm{S}_{\mathrm{pO}_{2}}$ and heart rate were registered during the night. Variation in $\mathrm{S}_{\mathrm{pO}_{2}}$ concentration was considered significant when oxygen desaturation was $\geq 4 \%$ over baseline saturation. The 


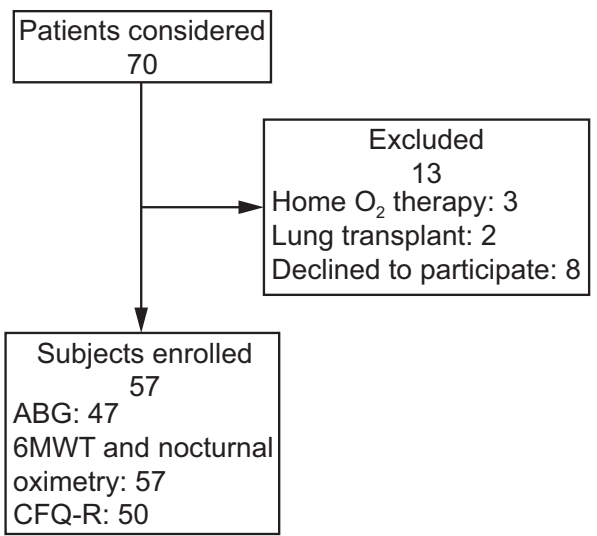

Fig. 1. Flow chart. $A B G=$ arterial blood gas; $6 \mathrm{WMT}=6$-min walk test; CFQ-R = Cystic Fibrosis Questionnaire-Revised.

number of these events per hour in the registry is known as desaturation index. Desaturation in the sleep study was defined when the desaturation index was $>4$ or when the sleep time with $\mathrm{S}_{\mathrm{pO}_{2}} \leq 90 \%$ was $>5 \%$, as described elsewhere. ${ }^{20-23}$

We analyzed the relationships between nocturnal desaturation and 6MWT with regard to gender, age, mutations, and comorbidities.

\section{Statistical Analysis}

Given a type one error of $5 \%$, with $19.3 \%$ of $6 \mathrm{MWT}$ desaturation and $57.9 \%$ of nocturnal desaturation, and the obtained sample size of 57 subjects, we determined that there was enough statistical power $(99.6 \%)$ to detect significant changes. We compared categorical variables with chi-square tests. The Kolmogorov-Smirnov test was performed to check the normality of continuous variables. For normally distributed data, we compared means using parametric tests such as Pearson, Student $t$, and analysis of variance. For non-normally distributed data, we used nonparametric tests such as Spearman, Friedman, and MannWhitney depending on the variables. In the descriptive analysis, the results were expressed as mean $\pm \mathrm{SD}$ for quantitative variables and as percentage for qualitative variables. Statistical significance was considered as $P<.05$. Results were analyzed with the statistical package SPSS version 15.0. (SPSS, Chicago, Illinois).

\section{Results}

Of 70 patients assessed for inclusion, 57 subjects were finally included. Thirteen patients were excluded: 3 subjects had home oxygen therapy, 2 were transplanted, and 8 declined to participate (Fig. 1). Males comprised 50.9\% of the subjects, with a mean age of $27.5 \pm 7.7 \mathrm{y}$ and a mean of $\mathrm{FEV}_{1}$ of $2.37 \pm 0.74 \mathrm{~L}^{2}$ and $\% \mathrm{FEV}_{1} 67 \pm 18.1 \%$.
Table 1. Demographic and Clinical Characteristics of Subjects

\begin{tabular}{|c|c|c|}
\hline Characteristics & Mean \pm SD & Range \\
\hline Age, y & $27.5 \pm 7.7$ & $18-54$ \\
\hline Body mass index, $\mathrm{kg} / \mathrm{m}^{2}$ & $21.9 \pm 2.9$ & $16.8-31.4$ \\
\hline Exacerbations in the previous year, no. & $2.6 \pm 1.7$ & $0-7$ \\
\hline $\begin{array}{l}\text { Hospital admissions in the previous } \\
\text { year, no. }\end{array}$ & $0.4 \pm 0.7$ & $0-4$ \\
\hline Shwachman-Kulczycki score $(n=50)$ & $82.1 \pm 11.9$ & $53-100$ \\
\hline Brasfield score $(n=54)$ & $19.0 \pm 3.9$ & $10-25$ \\
\hline Bhalla score $(n=54)$ & $14.7 \pm 3.8$ & $9-25$ \\
\hline $\mathrm{FEV}_{1}, \mathrm{~L}$ & $2.37 \pm 0.74$ & $0.9-4.5$ \\
\hline$\% \mathrm{FEV}_{1}$ & $67.0 \pm 18.1$ & $30-108$ \\
\hline Characteristics & \multicolumn{2}{|c|}{ Frequency, $n(\%)$} \\
\hline Male & \multicolumn{2}{|c|}{$29(50.9)$} \\
\hline 6MWT desaturation & \multicolumn{2}{|c|}{$11(19.3)$} \\
\hline Nocturnal desaturation & \multicolumn{2}{|c|}{$33(57.9)$} \\
\hline \multicolumn{3}{|l|}{ CFTR genotype } \\
\hline F508del/F508del & \multicolumn{2}{|c|}{$20(35.1)$} \\
\hline F508del/unknown & \multicolumn{2}{|c|}{$14(24.6)$} \\
\hline F508del/other & \multicolumn{2}{|c|}{$12(21.0)$} \\
\hline Other/other & \multicolumn{2}{|r|}{$5(8.7)$} \\
\hline Other/unknown & \multicolumn{2}{|r|}{$3(5.3)$} \\
\hline Unknown/unknown & \multicolumn{2}{|r|}{$3(5.3)$} \\
\hline
\end{tabular}

Table 1 summarizes the demographic and clinical characteristics of the study subjects.

Although the total lung capacity of all subjects remained within normal limits, the existence of air trapping was confirmed in $75.4 \%$ of subjects. Moreover, $71.9 \%$ of the subjects had lung hyperinflation (functional residual capacity $>120 \%)$. Only $47(82.5 \%)$ subjects in the study consented to perform a baseline arterial gasometry before the 6MWT.

Fifty subjects $(87.7 \%)$ completed the CFQ-R (see the supplementary materials at http://www.rcjournal.com), of whom $96 \%$ were of Spanish white origin, and $86 \%$ of the subjects had education levels higher than primary studies. The mean scores in the different sections of the CFQ-R ranged between 51.3 and 85.7 , being lower in the sections of burden of treatment, weight loss, respiratory symptoms, and health perception scores.

In the 6MWT, minimum saturations were obtained without having to stop walking, with a low of $78 \%$ in some subjects. According to the definition of desaturation in the 6MWT, 11 subjects $(19.3 \%)$ presented desaturation in the test, and $46(80.7 \%)$ did not.

The mean time spent sleeping at night was $6 \mathrm{~h}$ and $13 \mathrm{~min}$. The desaturation index was $6.4 \pm 6.5$ events per $\mathrm{h}$, the minimum $\mathrm{S}_{\mathrm{pO}_{2}}$ during sleep was $85.0 \pm 5.3 \%$, and sleep time with $\mathrm{S}_{\mathrm{pO}_{2}} \leq 90 \%$ was $13.7 \pm 26.7 \%$. According 
Table 2. Relationship Between Nocturnal Desaturation and 6MWT

\begin{tabular}{lrrrr}
\hline \hline & \multicolumn{4}{c}{ Nocturnal Desaturation } \\
\cline { 2 - 5 } & \multicolumn{1}{c}{ No } & \multicolumn{1}{c}{ Yes } & Total & $P=.27$ \\
\hline 6MWT Desaturation & & & & \\
$\quad$ No & $21(45.6)$ & $25(54.4)$ & $46(80.7)$ & \\
Yes & $3(23.3)$ & $8(72.7)$ & $11(19.3)$ & \\
Total & $24(42.1)$ & $33(57.9)$ & $57(100.0)$ \\
& & & & \\
\hline Data are presented as $n(\%)$. & & & & \\
\hline
\end{tabular}

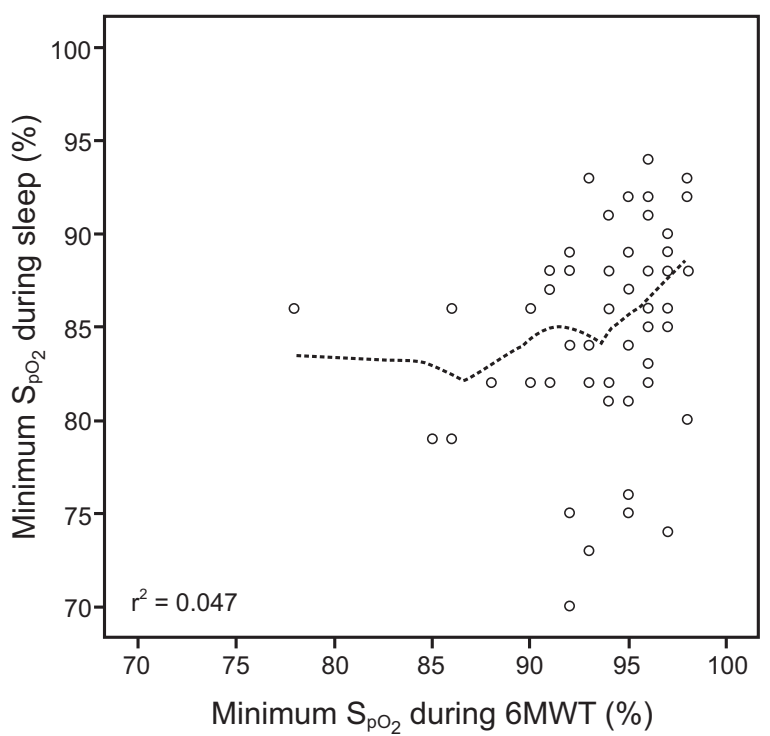

Fig. 2. Minimum oxygen saturation $\left(\mathrm{S}_{\mathrm{pO}_{2}}\right)$ during sleep and 6-min walk test (6MWT).

to the definition of desaturation during the sleep study, 33 subjects $(57.9 \%)$ presented nocturnal desaturation measured by pulse oximetry, and 24 subjects did not (42.1\%).

No relationship was observed between desaturation during the 6MWT and nocturnal desaturation $(P=.27 ; \mathrm{P}$ value relates patients with nocturnal desturation and 6MWT desaturation) (Table 2). Therefore desaturation cannot be considered a predictor of response between these 2 phenomena. In 11 subjects with desaturation in the 6MWT, $8(72.7 \%)$ had nocturnal desaturation versus $3(27.3 \%)$ who did not. This was not a statistically significant difference. Only $14 \%$ of subjects presented desaturation in both tests (Table 2, Fig. 2). No association $(P=.30)$ between the nocturnal desaturation measured by pulse oximetry with lung function $\left(\mathrm{FEV}_{1}\right.$ measured as a percentage of the theoretical value) was found. However, functional residual capacity was higher in subjects with desaturation statistically significant $(P=0.05)$ and also had higher RV (Table 3).

Of the 47 subjects who underwent blood gas analysis, $10(21.2 \%)$ had desaturation in the 6MWT. The mean baseline values of $\mathrm{P}_{\mathrm{aO}}, \mathrm{P}_{\mathrm{aCO}_{2}}$, and $\mathrm{S}_{\mathrm{aO}_{2}}$ in subjects with and without desaturation are shown in Table 3. Moreover, 26 subjects $(55.3 \%)$ presented with nocturnal desaturation. These subjects had higher mean levels of carbon dioxide and lower oxygen levels than those who did not desaturate. There were significant differences in the $\mathrm{P}_{\mathrm{aO}}$ and $\mathrm{P}_{\mathrm{aCO}}$ levels, but not in baseline $\mathrm{S}_{\mathrm{aO}_{2}}(P=.002, P=.01$, and $P=.055$, respectively) (Table 3 ).

The average score of the respiratory symptoms item in the CFQ-R in subjects with desaturation during the 6MWT was $64.2 \pm 17.1$, which was slightly less than those who did not desaturate without reaching a significant difference $(P=.60)$ (see the supplementary materials at http:// www.rcjournal.com).

Neither nocturnal desaturation nor the respiratory domain of the CFQ-R were significantly related $(P=.37)$. The average score that item was lower in subjects with nocturnal desaturation $(64.7 \pm 16.4)$ compared to other subjects (68.4 \pm 16.8). A significant relationship with other items on the questionnaire were found as digestive $(P=.009)$ and emotional $(P=.050)$.

No association between BMI and 6MWT $(P=.24)$ was identified, although the mean BMI of subjects with desaturation in the $6 \mathrm{MWT}\left(21.0 \pm 3.1 \mathrm{~kg} / \mathrm{m}^{2}\right)$ tended to be lower than that of subjects who did not desaturate $\left(22.1 \pm 2.8 \mathrm{~kg} / \mathrm{m}^{2}\right)$.

There was no association between nocturnal desaturation and BMI $(P=.42)$, and in this case the mean BMI of subjects with nocturnal desaturation $\left(22.2 \pm 3.2 \mathrm{~kg} / \mathrm{m}^{2}\right)$ was not significantly higher that the BMI of those who did not desaturate $\left(21.6 \pm 2.5 \mathrm{~kg} / \mathrm{m}^{2}\right)$.

Finally, there were statistically significant differences in the nocturnal desaturation by sex $(P=.02)$; male subjects had higher nocturnal desaturation than female subjects (Table 4; P value relates nocturnal desaturation and male). We found no association of nocturnal desaturation with all other variables, such as the type of mutation, pancreatic insufficiency, or diabetes.

\section{Discussion}

We observed that desaturation during 6MWT in subjects with $\mathrm{CF}$ did not predict desaturation at night. However, subjects with $\mathrm{FEV}_{1} \leq 55 \%, \mathrm{D}_{\mathrm{LCO}} \leq 50 \mathrm{mmol} / \mathrm{min} / \mathrm{mm} \mathrm{Hg}$, and baseline $\mathrm{S}_{\mathrm{aO}_{2}} \leq 94 \%$ have a higher risk of desaturation in the 6MWT. Furthermore, being male with a $\mathrm{P}_{\mathrm{aO}_{2}} \leq 71 \mathrm{~mm} \mathrm{Hg}$ in arterial blood gas analysis increases the risk of nocturnal desaturation. We suggest that the lower frequency in nocturnal desaturation in women may be due to anatomical or hormonal factors.

Nocturnal pulse oximetry is a clinically useful test to detect hypoxemia during sleep, as shown in previous studies such as Montgomery et al, ${ }^{22}$ where it was reported that subjects with $\mathrm{CF}$ who had $\mathrm{P}_{\mathrm{aO}_{2}}$ concentration $<60 \mathrm{~mm} \mathrm{Hg}$ 
Table 3. Test Results for 6MWT Desaturation and Nocturnal Desaturation Groups

\begin{tabular}{|c|c|c|c|c|c|c|}
\hline & \multicolumn{3}{|c|}{ 6MWT Desaturation Group } & \multicolumn{3}{|c|}{ Nocturnal Desaturation Group } \\
\hline & No & Yes & $P$ & No & Yes & $P$ \\
\hline Subjects, $n(\%)$ & $46(80.7 \%)$ & $11(19.3 \%)$ & & $24(42.1 \%)$ & $33(57.9 \%)$ & \\
\hline $\mathrm{FEV}_{1}, \mathrm{~L}$ & $2.50 \pm 0.71$ & $1.82 \pm 0.59$ & .004 & $2.31 \pm 0.41$ & $2.41 \pm 0.90$ & .62 \\
\hline$\% \mathrm{FEV}_{1}$ & $70.2 \pm 15.4$ & $53.3 \pm 22.4$ & .004 & $69.8 \pm 14.4$ & $64.9 \pm 20.3$ & .30 \\
\hline FVC, L & $3.66 \pm 0.86$ & $2.91 \pm 0.53$ & .001 & $3.36 \pm 0.61$ & $3.63 \pm 0.99$ & .21 \\
\hline$\% \mathrm{FVC}$ & $83.5 \pm 12.8$ & $67.8 \pm 13.0$ & .001 & $83.3 \pm 11.8$ & $78.4 \pm 15.5$ & .20 \\
\hline $\mathrm{FEV}_{1} / \mathrm{FVC}$ & $68.8 \pm 9.3$ & $62.4 \pm 16.1$ & .09 & $69.2 \pm 9.8$ & $66.3 \pm 11.9$ & .35 \\
\hline TLC, L & $5.77 \pm 1.06$ & $5.76 \pm 1.01$ & .99 & $5.29 \pm 0.94$ & $6.10 \pm 0.99$ & .057 \\
\hline$\% \mathrm{TLC}$ & $103.6 \pm 12.3$ & $107.8 \pm 10.2$ & .35 & $104.5 \pm 10.5$ & $104.3 \pm 13.1$ & .95 \\
\hline Residual volume/TLC & $140.7 \pm 35.3$ & $164.2 \pm 31.8$ & .07 & $133.6 \pm 30.0$ & $152.7 \pm 37.4$ & .07 \\
\hline $\mathrm{D}_{\mathrm{LCO}}, \mathrm{mmol} / \mathrm{min} / \mathrm{mm} \mathrm{Hg}$ & $60 \pm 12.75$ & $50.25 \pm 9.0$ & .041 & $57.75 \pm 12.0$ & $59.25 \pm 13.5$ & .74 \\
\hline$\% \mathrm{D}_{\mathrm{LCO}}$ & $81.2 \pm 14.7$ & $69.5 \pm 10.4$ & .03 & $81.7 \pm 13.1$ & $77.4 \pm 15.6$ & .31 \\
\hline Body mass index & $22.15 \pm 2.82$ & $20.99 \pm 3.11$ & .24 & $21.57 \pm 2.49$ & $22.19 \pm 3.16$ & .43 \\
\hline Arterial blood gases, $n(\%)$ & $37(78.8 \%)$ & $10(21.2 \%)$ & & $21(44.7 \%)$ & $26(55.3 \%)$ & \\
\hline $\mathrm{P}_{\mathrm{O}_{2}}, \mathrm{~mm} \mathrm{Hg}$ & $80.9 \pm 10.2$ & $74.0 \pm 12.2$ & .08 & $84.7 \pm 9.6$ & $75.3 \pm 10.2$ & .002 \\
\hline $\mathrm{P}_{\mathrm{CO}_{2}}, \mathrm{~mm} \mathrm{Hg}$ & $35.5 \pm 4.6$ & $34.9 \pm 3.7$ & .69 & $33.6 \pm 3.7$ & $36.8 \pm 4.4$ & .01 \\
\hline $\mathrm{S}_{\mathrm{aO}_{2}}$, baseline $(\%)$ & $95.5 \pm 1.7$ & $93.9 \pm 2.5$ & .054 & $95.8 \pm 1.8$ & $94.7 \pm 2.0$ & .047 \\
\hline \multicolumn{7}{|c|}{$\begin{array}{l}\text { Data are presented as mean } \pm \mathrm{SD} \text { unless noted as } n(\%) \\
\% \mathrm{FEV} V_{1}=\% \text { of the theoretical value of } \mathrm{FEV} \\
\% \mathrm{FVC}=\% \text { of the theoretical value of } \mathrm{FVC} \\
\mathrm{TLC}=\text { total lung capacity } \\
\% \mathrm{TLC}=\% \text { of the theoretical value of } \mathrm{TLC} \\
\mathrm{D}_{\mathrm{LCO}}=\text { diffusing capacity for carbon monoxide } \\
{ }_{\mathrm{L}} \mathrm{D}_{\mathrm{LCO}}=\% \text { of the theoretical value of } \mathrm{D}_{\mathrm{LCO}}\end{array}$} \\
\hline
\end{tabular}

Table 4. Sex and Nocturnal Desaturation

\begin{tabular}{lrcr}
\hline \hline & \multicolumn{3}{c}{ Nocturnal Desaturation } \\
\cline { 2 - 4 } & \multicolumn{1}{c}{ No } & Yes & $P=.02$ \\
\hline Sex & & & \\
$\quad$ Male $(n=29)$ & $8(27.6)$ & $21(72.4)$ & \\
Female $(n=28)$ & $16(57.1)$ & $12(42.9)$ & \\
Total $(N=57)$ & $24(42.1)$ & $33(57.9)$ & \\
\hline Data are presented as $n(\%)$. & & & \\
\hline
\end{tabular}

daily experienced $>80 \%$ of sleeping time with an $\mathrm{S}_{\mathrm{pO}_{2}}$ $<90 \%$ on a daily basis. In the study by Frangolias and Wilcox, ${ }^{20}$ while $40 \%$ of the subjects had nocturnal desaturation, which was related to clinical, radiological, and spirometric variables, the investigators were unable to find a predictive factor for nocturnal desaturation and thus concluded that nocturnal desaturation with $\% \mathrm{FEV}_{1}>65 \%$ was infrequent but expected when baseline $\mathrm{S}_{\mathrm{aO}_{2}}$ was $<93 \%$. Two other studies suggested that an $\mathrm{FEV}_{1}<65 \%$ predicted could predict hypoxemia during sleep in subjects with CF. ${ }^{24,25}$ Another study in a pediatric population in which pulse oximetry was used correlated $\mathrm{S}_{\mathrm{pO}_{2}}<90 \%$ at night with $\mathrm{FEV}_{1}{ }^{26}$ These results are consistent with ours in that subjects with nocturnal desaturation usually present with an $\mathrm{FEV}_{1}<65 \%$ predicted, along with a $\mathrm{P}_{\mathrm{aO}_{2}}$ $\leq 71 \mathrm{~mm} \mathrm{Hg}$. We observed nocturnal desaturation in a high percentage of subjects without clinical suspicion. Perhaps this is why more factors that can predict nocturnal desaturation should be studied as a factor in disease progression.

According to Coffey et al, ${ }^{25}$ hypoxemia in CF occurs more frequently during sleep than during exercise, suggesting that sleep studies may be indicated in patients with $\mathrm{CF}$ and hypoxemia during exercise. However, in our study, no 6MWT clinical marker was found to predict nocturnal desaturation. It is likely that the mechanisms of hypoxemia during exercise differ from those during sleep, as demonstrated by the absence of a correlation between measurements in the studies. Another reason for this lack of correlation may be the type of exercise test or submaximal effort by subjects. Different mechanisms, including hypoventilation and changes in ventilation-perfusion relationships, are related to sleep desaturations. On the other hand, exercise-induced desaturations are associated with increased expiratory air-flow resistance and increased deadspace ventilation. ${ }^{25,27}$

The 6MWT can be viewed as a submaximal exercise, but it is considered to be inaccurate in older subjects with poorer lung function. In the study by Gruet et al, ${ }^{28}$ subjects with CF had worse outcomes than controls, unlike previous studies such as that performed by Chetta et al. ${ }^{29}$ Gruet et al ${ }^{28}$ observed that one third of subjects with $\mathrm{CF}$ desatu- 


\section{MWT and Predicting Nocturnal Desaturations in CF}

rated during the 6MWT but not during cardiopulmonary exercise testing. These subjects also walked less than the control group. The results of this study suggest that $6 \mathrm{MWT}$ desaturation is a better predictor of the maximum cardiopulmonary exercise outcome. However, in the study by Chetta et al, ${ }^{29} \mathrm{CF}$ participants with mild/moderate lung function walked the same distance as control subjects but experienced a significant drop in $\mathrm{S}_{\mathrm{pO}_{2}}$ and a greater perception of dyspnea during exercise. They concluded that the 6MWT could be valuable to identify patients who could experience oxygen desaturation and dyspnea during daily activities that require greater effort.

In our study, 6MWT desaturation was associated with $\mathrm{FEV}_{1} \%$ predicted and $\mathrm{D}_{\mathrm{LCO}}$. These results were similar to those of other studies, although in previous studies, the distance walked in the 6MWT was the associative factor. Martin et al ${ }^{5}$ found that the 6MWT correlated with $\mathrm{FEV}_{1}$, indicating that exercise capacity decreased with increase of air-flow limitation in adults with CF. Other studies, such as that by Okuro et al, ${ }^{30}$ showed the importance of distance walked in the 6MWT as both a complementary outcome and tool to provide information on exercise response.

The 6MWT may not require enough effort to produce desaturation, which may be why a relationship with nocturnal desaturation was not found. There is another exercise test, the 6-min step test, that requires more effort and may produce more frequent desaturation. It could be a good predictor test and could be validated for patients with $\mathrm{CF}$ as it has been for patients with COPD. ${ }^{31,32}$ This is a relatively new area that deserves further study.

Quality of life for patients with CF may be influenced by low oxygen levels in the blood. ${ }^{33}$ When exploring desaturation in the 6MWT and the sleep study with the respiratory section of the CFQ-R questionnaire, we found no association. The CFQ-R questionnaire is a useful and easy tool to study quality of life in patients with $\mathrm{CF}$, but there is no research on using the CFQ- R questionnaire in relation to desaturation. The only study of quality of life and home oxygen therapy in subjects with $\mathrm{CF}$ showed that, for 12 months, attendance at school and at work remained at $83 \%$ for the oxygen-treated group, compared to $20 \%$ in those who did not receive oxygen. ${ }^{33}$ It was further noted that both sleep quality and duration have a correlation with nighttime $\mathrm{S}_{\mathrm{pO}_{2}}$. However, no relation to mortality, hospitalizations, or disease progression was found.

We believe that the subjects in our study constitute a representative sample of the overall population of adults with $\mathrm{CF}$ because they came from the catchment population of our hospital plus various regions in Spain, and they included a broad spectrum of subjects of both sexes and a wide age range.

However, some potential limitations deserve discussion. CF is not a highly prevalent disease, so the study sample is reduced. This was an adult population in stable condition, so many of them enjoy an optimal respiratory status. In addition, subjects who already had home oxygen therapy were excluded. The potential exclusion of these more serious cases could lead to an underestimation of the true impact of the disease on desaturation in the 6MWT and at night. In the future, we can extend this study with other hospitals to obtain a larger sample size, to confirm the results, and to include participants with greater disease severity.

\section{Conclusion}

Desaturation observed during the 6MWT in subjects with $\mathrm{CF}$ does not predict desaturation at night. $\% \mathrm{FEV}_{1}$ and $\mathrm{D}_{\mathrm{LCO}}$ are factors that influence desaturation in the 6MWT. Nocturnal desaturation occurs more often in males with low levels of $\mathrm{P}_{\mathrm{aO}_{2}}$ in blood gases. Nocturnal pulse oximetry can be a useful test to detect nocturnal desaturation in patients without clinical suspicion.

\section{REFERENCES}

1. Salvatore D, Buzzetti R, Baldo E, Furnari ML, Lucidi V, Manunza $\mathrm{D}$, et al. An overview of international literature from cystic fibrosis registries. Part 4: update 2011. J Cyst Fibros 2012;11(6):480-493.

2. Morales P, Sánchez E. Identificación, estructura y expresión del gen CFTR. In: Salcedo A, Gartner S, Girón RM, and García MD, editors Tratado de Fibrosis Quística. Madrid: Editorial Justim; 2012:29-40.

3. Cystic Fibrosis Foundation Patient Registry. 2015 Annual Data Report. Bethesda: Maryland; 2016:6-7.

4. Cahalin L, Pappagianopoulos P, Prevost S, Wain J, Ginns L. The relationship of the 6-min walk test to maximal oxygen consumption in transplant candidates with end-stage lung disease. Chest 1995; 108(2):452-459.

5. Martin C, Chapron J, Hubert D, Kanaan R, Honoré I, Paillasseur JL, et al. Prognostic value of six minute walk test in cystic fibrosis adults. Respir Med 2013;107(12):1881-1887.

6. Bradley S, Solin P, Wilson J, Johns D, Walters EH, Naughton MT. Hypoxemia and hypercapnia during exercise and sleep in patients with cystic fibrosis. Chest 1999;116(3):647-654.

7. De Castro-Silva C, de Bruin VM, Cavalcante AG, Bittencourt LR, de Bruin PF. Nocturnal Hypoxia and Sleep Disturbances in Cystic Fibrosis. Pediatr Pulmonol 2009;44(11):1143-1150.

8. Villa MP, Pagani J, Lucidi V, Palamides S, Ronchetti R. Nocturnal oximetry in infants with cystic fibrosis. Arch Dis Child 2001;84(1): 50-54.

9. García Hernández G, Martínez Martínez MT. Protocolo de control y seguimiento. In: Salcedo A, Gartner S, Girón RM, and García MD, eds. Tratado de Fibrosis Quística. Madrid: Editorial Justim; 2012: 139-147.

10. Uyan ZS, Ozdemir N, Ersu R, Akpinar I, Keskin S, Cakir E. Factors that correlate with sleep oxygenation in children with cystic fibrosis. Pediatr Pulmonol 2007;42(8):712-716.

11. Urquhart DS, Montgomery H, Jaffé A. Assessment of hypoxia in children with cystic fibrosis. Arch Dis Child 2005;90(11):1138-1143.

12. Gartner $\mathrm{S}$, Cobos N. Cribado neonatal para la fibrosis quística (editorial). An Pediatr (Barc) 2009;71(6):481-482.

13. Barrio Gómez de Agüero MI, García Hernández G, Gartner S, Cystic Fibrosis Working Group. Protocolo de diagnóstico y seguimiento de 


\section{MWT and Predicting Nocturnal Desaturations in CF}

los pacientes con fibrosis quística. An Pediatr (Barc) 2009;71(3): 250-264.

14. Sinaasappel M, Stern M, Littlewood J, Wolfe S, Steinkamp G, Heijerman $\mathrm{HG}$, et al. Nutrition in patients with cystic fibrosis: a European consensus. J Cyst Fibros 2002;1(2):51-75.

15. Shwachman H, Kulczycki LL. Long term study of 105 patients with cystic fibrosis. Am J Dis Child 1958;96:6-10.

16. Brasfield D, Hicks G, Soong S, Peters J, Tiller R. Evaluation of scoring system of the chest radiograph in cystic fibrosis: a collaborative study. AJR Am J Roentgenol 1980;134(6):1195-1198.

17. Albi G, Rayón-Aledo JC, Caballero P, Rosado P, García-Esparza E. Fibrosis quística en imágenes. Clasificación de Bhalla para la tomografía computarizada en pacientes pediátricos. Radiología 2012; 54(3):260-268.

18. Quittner AL, Buu A, Messer MA, Modi AC, Watrous M. Development and validation of the Cystic Fibrosis Questionnaire in the United States: a health-related quality-of-life measure for cystic fibrosis. Chest 2005;128(4):2347-2354.

19. ATS Committee on Proficiency Standards for Clinical Pulmonary Function Laboratories. ATS Statement: Guidelines for the six-minute walk test. Am J Respir Crit Care Med 2002;166(1):111-117.

20. Frangolias DD, Wilcox PG. Predictability of oxygen desaturation during sleep in patients with cystic fibrosis. Chest 2001;119(2):434-441.

21. Smith DL, Freeman W, Cayton RM, Stableforth DE. Nocturnal hypoxemia in CF: relationship to pulmonary function tests. Respir Med 1994;88(7):537-539.

22. Montgomery M, Wiebicke W, Bibi H, Pagtakhan RD, Pasterkamp H. Home measurement of oxygen saturation during sleep in patients with cystic fibrosis. Pediatr Pulmonol 1989;7(1):29-34.

23. Braggion C, Pradal U, Mastella G. Haemoglobin desaturation during sleep and daytime in patients with cystic fibrosis and severe airway obstruction. Acta Paediatr 1992;81(12):1002-1006.
24. Versteegh FG, Bogaard JM, Raatgever JW, Stam H, Neijens HJ, Kerrebijn KF. Relationship between airway obstruction, desaturation during exercise and nocturnal hypoxemia in cystic fibrosis patients. Eur Resp J 1990;3(1):68-73.

25. Coffey MJ, Fitzgerald MX, McNicholas WT. Comparison of oxygen desaturation during sleep and exercise in patients with cystic fibrosis. Chest 1991;100(3):659-662.

26. Van der Giessen L, Bakker M, Joosten K, Hop W, Tiddens H. Nocturnal oxygen saturation in children with stable cystic fibrosis. Pediatr Pulmonol 2012;47(11):1123-1130.

27. Amann M. Pulmonary system limitations to endurance exercise performance in humans. Exp Physiol 2012;97(3):311-318.

28. Gruet M, Brisswalter J, Mely L, Vallier JM. Use of the peak heart rate reached during six-minute walk test to predict individualized training intensity in patients with cystic fibrosis: validity and reliability. Arch Phys Med Rehabil 2010;91(4):602-607.

29. Chetta A, Pisi G, Zanini A, Foresi A, Grzincich GL, Aiello M, et al Six-minute walking test in cystic fibrosis adults with mild to moderate lung disease: comparison to healthy subjects. Respir Med 2001; 95(12):986-991.

30. Okuro RT, Oliveira Ribeiro MA, Ribeiro JD, Minsky RC, Schivinski CI. Alternative indexes to estimate the functional capacity from the 6-minute walk test in children and adolescents with cystic fibrosis. Respir Care 2017;62(3):324-332.

31. Grosbois JM, Riquier C, Chehere B, Coquart J, Béhal H, Bart F, et al. Six-minute stepper test: a valid clinical exercise tolerance test for COPD patients. Int J Chron Obstruct Pulmon Dis 2016;11:657-663.

32. Coquart JB, Lemaître F, Castres I, Saison S, Bart F, Grosbois JM. Reproducibility and sensitivity of the 6-minute stepper test in patients with COPD. COPD 2015;12(5):533-538.

33. Zinman R, Corey M, Coates AL, Canny GJ, Connolly J, Levison H, et al. Nocturnal home oxygen in the treatment of hypoxemic cystic fibrosis patients. J Pediatr 1989;114(3):368-677. 